\title{
Spontaneous Resolution Rates of Vesicoureteral Reflux in Brazilian Children: A 30-Year Experience
}

\author{
Miguel Zerati Filho, Adriano A. Calado, Ubirajara Barroso Jr, Joao L. Amaro \\ Division of Urology, Sao Paulo State University, UNESP, Botucatu, Sao Paulo, Brazil
}

\begin{abstract}
Objective: We evaluated clinical characteristics of primary vesicoureteral reflux (VUR) in infants in a 30-year period in Brazil with special reference to the relation of renal parenchymal damage to urinary tract infection and gender.

Materials and Methods: From 1975 through 2005, 417 girls (81.6\%) and 94 boys (18.4\%) with all grades of reflux were retrospectively reviewed. Patients were categorized by the worst grade of reflux, maintained on antibiotic prophylaxis and underwent yearly voiding cystourethrography until the reflux was resolved. VUR was considered resolved when a followup cystogram demonstrated no reflux. Surgical correction was recommended for those who fail medical therapy, severe renal scarring or persistent VUR.

Results: Grades I to V VUR resolved in $87.5 \%, 77.6 \%, 52.8 \%, 12.2 \%$ and $4.3 \%$, respectively. Renal scars were present at presentation in 98 patients $(19.2 \%)$. Neither gender nor bilaterality versus unilaterality was a helpful predictor of resolution. The significant difference was found among the curves using the log rank $(\mathrm{p}<0.001)$ or Wilcoxon $(\mathrm{p}<0.001)$ test.

Conclusion: Despite the current use of screening prenatal ultrasound, many infants are still diagnosed as having vesicoureteral reflux only after the occurrence of urinary tract infection in our country. Scarring may be associated to any reflux grade and it may be initially diagnosed at any age but half of the scars are noted with higher grades of reflux (IV and V). The incidence of reflux related morbidity in children has significantly diminished over the last three decades.
\end{abstract}

Key words: ureter; vesico-ureteral reflux; reconstructive surgical procedures

Int Braz J Urol. 2007; 33: 204-15

\section{INTRODUCTION}

Vesicoureteral reflux (VUR) is a common pediatric problem. The possibility of renal damage due to VUR and consequently renal function impairment and hypertension gives the necessary impetus for the diagnosis or exclusion of this problem (1). In general, it was thought that medical and surgical management represented equally efficacious treatment options $(1,2)$. Both treatment forms have advantages and disadvan- tages that must be taken into account and shared with the parents when choosing the best approach. If, on one hand, clinical treatment requires chronic antibiotic prophylaxis, periodic surveillance of urine cultures and periodic voiding cystourethrograms (VCUGs), which despite the low morbidity may cause discomfort, on the other hand, surgery is related to the risks of a surgical-anesthetic procedure.

Several studies carried out in Europe and in the United States have established the rates of spon- 
taneous resolution for patients with VUR undergoing medical management. Due to the lack of similar data in our country, specialists have used these data for management of the patients.

The primary endpoint of this study was defining the rates of spontaneous resolution for patients with VUR in our country. These data may be helpful to determine the need for surgical intervention and the proper follow-up schedule in patients on antibiotic prophylaxis.

On the other hand, the group selected in this report, which was conservatively managed over a 30 -year period, is of particular interest in understanding the changes in the approach of VUR in this period of time. Besides finding out the overall resolution rate, we saw if we could find differences between the groups according to the period diagnosis was carried out.

\section{MATERIALS AND METHODS}

Of the 813 consecutive patients with VUR treated at our institution from January 1975 to December 2005, 302 were excluded because in 121 a VCUG was not repeated, in 105 follow-up were insufficient $(<12$ months) and 76 children had secondary VUR. 511 children were retrospectively evaluated and met the inclusion criteria: a) age $<10$ years at the time of diagnosis; b) radiological tests confirming VUR and VUR grade; c) minimum follow-up time of 12 months; d) no voiding dysfunction, neuropathic bladder, duplicated systems, ectopic ureters, ureterocele, and other associated pathologies. VUR was detected by VCUG and the grade classified according to the International Reflux Study Committee (3).

The renal parenchyma was evaluated using renal cortical scintigraphy (99mTc-DMSA), intravenous urography or both (4-6). Patients were kept under continuous prophylaxis and had urine culture collected on a monthly basis, upper urinary tract assessment with renal ultrasonography (RUS) every six months and intravenous urography or scintigraphy and VCUG once a year. Reflux was considered resolved when absent on a single cystogram.
Patients with any of the following parameters underwent surgery: failure of medical management (breakthrough urinary tract infections and patient noncompliance), increase or development of new renal scars and reflux that fails to resolve (mainly grade IV or $\mathrm{V}$ ).

After obtaining demographic data, patients were divided into three groups according to the period diagnosis was carried out: Group $\mathrm{A}(\mathrm{n}=80)$ from 1975 to 1985; Group B $(n=205)$ from 1986 to 1995 ; Group C $(n=226)$ from 1996 to 2005.

The results were statistically analyzed using the Minitab ${ }^{\circledR}$ statistical computing software, with $\mathrm{p}<$ 0.05 considered to indicate statistical significance. Kaplan-Meier curves were constructed to estimate the reflux resolution rate per grade and the rates were compared using the log rank and Wilcox on tests. Data shown in the tables were analyzed by the chi-square test. The study protocol was reviewed and approved by the local ethics committee.

\section{RESULTS}

The initial clinical manifestation leading to the diagnosis of VUR in $85 \%$ of the cases was urinary tract infection, confirmed by urinary culture, followed by fever of indeterminate cause (5.4\%), lumbar pain (3.5\%), antenatal hydronephrosis (2.9\%), hematuria $(2.5 \%)$ and others. Mean age at presentation was 3.1 years and median follow-up was 2.7 years $(1.2$ - 12.4 years). VUR was unilateral in $250(48.9 \%)$ and bilateral in $261(51.1 \%)$ cases. Grade II VUR was detected more frequently (192 cases $-37.6 \%$ ), followed by grade III (174 cases - 34\%), grade IV (74 cases $14.5 \%)$, grade I (48 cases $-9.4 \%)$ and grade V (23 cases $-4.5 \%)$.

We observed an incidence 4 times greater in females than in males ( $81.6 \%$ against $18.4 \%$ ). When patients were stratified according to age at diagnosis, it was observed that the number of boys with VUR decreases with age, ranging from $29.4 \%$ in the first year of life to $10.2 \%$ in children over 5 years of age. One hundred and twenty female patients $(70.6 \%)$ had a diagnosis of VUR before 1 year of age, whereas $89.8 \%$ (70/ 78) girls had a diagnosis of VUR over 5 years of age. 
The large majority of diagnosis, 344 (67.3\%), was made before the $3^{\text {rd }}$ year of life, of which 170 $(33.2 \%)$ before the first year (Figure-1). The stratification of patients according to VUR grade shows a similar distribution among the three groups (Table-1). There was no significant difference among the study groups (A, B and C) for the severity of VUR. Table2 shows the tests carried out in the initial evaluation of the patients in the study groups. For the statistical analysis, groups A and B were analyzed together due to the small sample of patients who carried out RUS and DMSA scan in group A. In the first period, intravenous urography was carried out in $93.7 \%$ of the cases and RUS and DMSA scan in 1.2\% and $13.7 \%$ respectively. In the last decade there is an important change, and intravenous urography is used in only $21.2 \%$ of the children and RUS and scintigraphy is used in $88 \%$ and $23.4 \%$ respectively. There is a significant difference between groups $(\mathrm{A}+\mathrm{B})$ and $\mathrm{C}$ for the use of RUS, scintigraphy and intravenous urography $(\mathrm{p}<0.001)$.
Patients were also evaluated for the presence of renal scars at the time of diagnosis. In group A, 31.2\% (25/80) had renal scars, in group B, 20.5\% $(42 / 205)$; and in group C, $13.7 \%$ (31/226) (Figure2 ). There was a significant difference between groups for the presence of renal scars in the initial evaluation $(\mathrm{p}=0.02)$, with a clear decrease of renal scars in the last period, from 1996 to 2005. Table-3 stratifies patients with renal scars according to age at the presentation. There is a clear correlation between age and renal scars, which are significantly more frequent in the group of patients over 5 years of age $(\mathrm{p}<0.001)$.

Of the 125 patients requiring surgery, $30 \%$ (24/80) were from Group A, 30.2\% (62/205) from Group B and 17.2\% (39/226) from Group C. When the number of surgical procedures is compared, a significant difference is observed between Groups $A$ and B compared to Group C $(p=0.003)$, with a clear decrease of surgical indications over time. In the overall characteristics of patients (Table-4), severe cases of

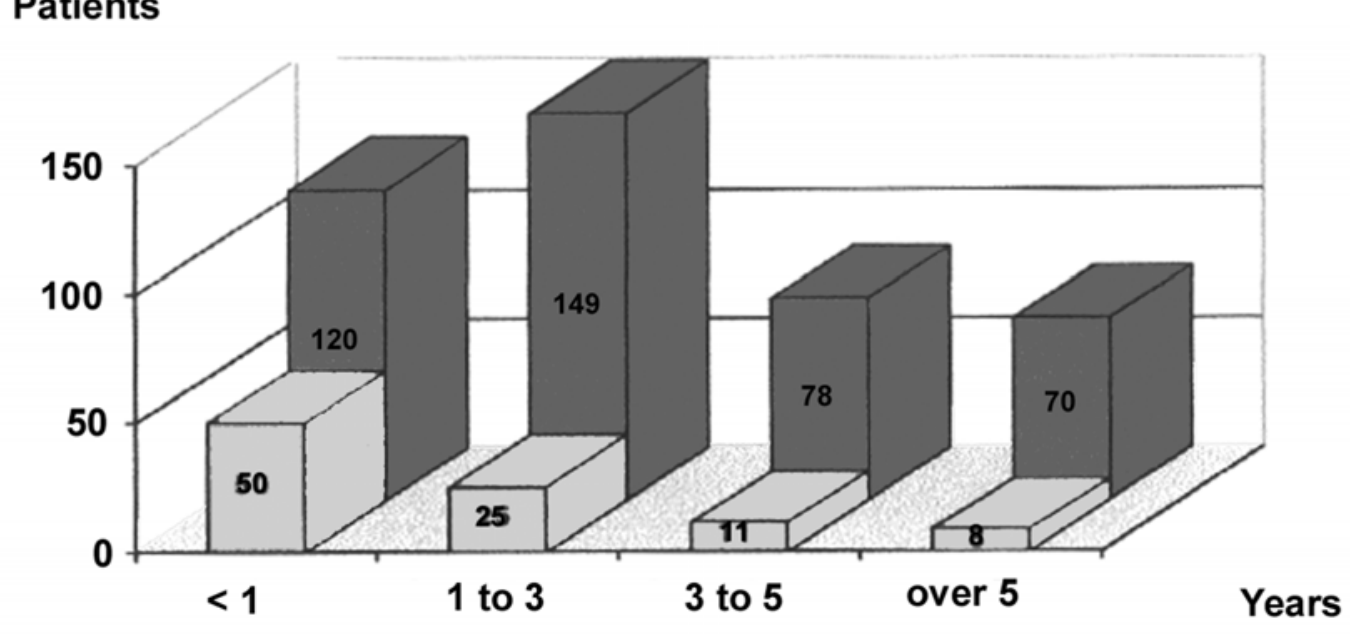

Figure 1 - Distribution of 511 children with vesicoureteral reflux undergoing treatment, divided according to gender and age. 
Table 1 - The distribution of reflux grades according to the study groups.

\begin{tabular}{lccc}
\hline & $\mathbf{1 9 7 5 - 1 9 8 5}$ & $\mathbf{1 9 8 6 - 1 9 9 5}$ & $\mathbf{1 9 9 6 - 2 0 0 5}$ \\
$\mathbf{N}(\boldsymbol{\%})$ & $\mathbf{N}(\boldsymbol{\%})$ & $\mathbf{N})$ \\
\hline Grade I & $\mathbf{N}(11.8 \%)$ & $17(8.3 \%)$ & $22(9.5 \%)$ \\
Grade II & $28(36.8 \%)$ & $80(39.2 \%)$ & $76(36.4 \%)$ \\
Grade III & $26(34.2 \%)$ & $72(35.3 \%)$ & $33(14.3 \%)$ \\
Grade IV & $14(18.4 \%)$ & $27(13.2 \%)$ & $11(4.8 \%)$ \\
Grade V & $3(3.9 \%)$ & $9(4.4 \%)$ & $226(100 \%)$ \\
Total & $80(100 \%)$ & $205(100 \%)$ & \\
\hline
\end{tabular}

$p>0.05$

Table 2 - Tests carried out in the initial evaluation of the patients in the study groups.

\begin{tabular}{lccc}
\hline & $\begin{array}{c}\mathbf{1 9 7 5 - 1 9 8 5} \\
\mathbf{N}(\%)\end{array}$ & $\begin{array}{c}\mathbf{1 9 8 6 - 1 9 9 5} \\
\mathbf{N}(\boldsymbol{\%})\end{array}$ & $\begin{array}{c}\mathbf{1 9 9 6 - 2 0 0 5} \\
\mathbf{N}(\boldsymbol{\%})\end{array}$ \\
\hline Renal ultrasound & $1(1.2 \%)$ & $61(29.7 \%)$ & $199(88 \%)$ \\
Renal scintigraphy (DMSA) & $11(13.7 \%)$ & $30(14.6 \%)$ & $53(23.4 \%)$ \\
Intravenous urography & $75(93.7 \%)$ & $163(79.5 \%)$ & $48(21.2 \%)$ \\
Total & $87(\mathrm{n}=80)$ & $254(\mathrm{n}=205)$ & $300(\mathrm{n}=226)$ \\
\hline
\end{tabular}

$p<0.001$

reflux (IV and V) are observed in 19\% of the children and the incidence of renal injury is proportional do VUR grade, i.e., the more intensive the VUR, the greater is the probability of developing scars. However, even low grade VUR (I and II) was associated with renal scarring in this cohort.

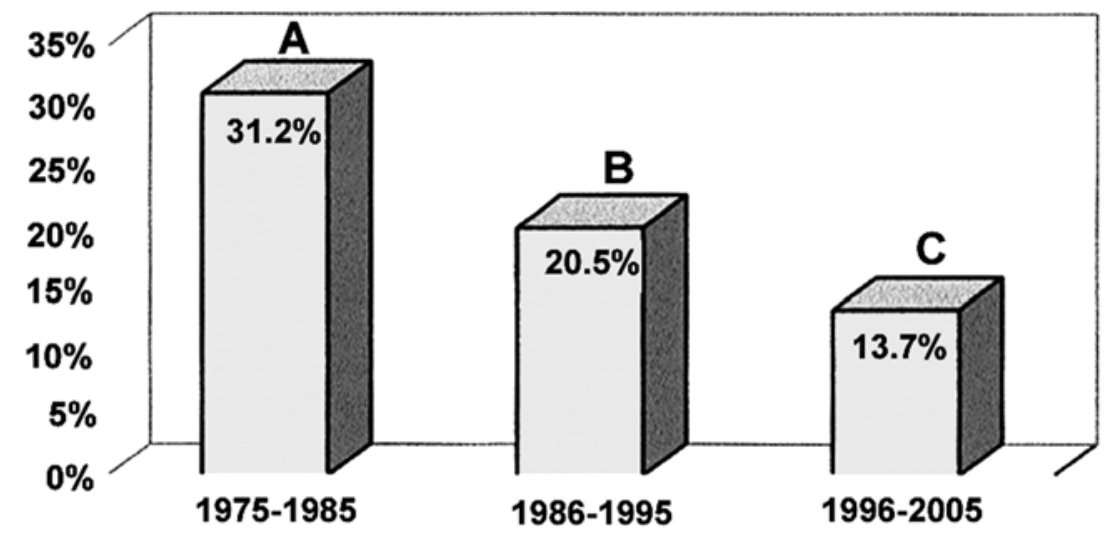

Figure 2 - Presence of renal scars at the time of diagnosis $(n=511)$, at the diferents groups; $p=0.02$. 
Table 3 - Patients with renal scars according to age at the presentation.

\begin{tabular}{lcc}
\hline Age (years) & Patients $(\mathrm{N})$ & Renal Scars $-\mathrm{N}(\%)$ \\
\hline$<1$ & 170 & $20(11.8 \%)$ \\
$1-3$ years & 174 & $20(11.5 \%)$ \\
$3-5$ years & 89 & $16(18 \%)$ \\
$>5$ years & 78 & $42(53.8 \%)$ \\
\hline$p<0.001$ &
\end{tabular}

When the rates of spontaneous resolution of reflux were analyzed for different grades of VUR throughout the medical management, 87.5\% (42/48) of the patients with VUR grade I; 77.6\% (149/192) of patients with VUR grade II and 52.8\% (92/174) of patients with VUR grade III had spontaneous resolution (Figure-3). Of the 74 patients with VUR grade IV, spontaneous resolution was observed in $9(12.2 \%)$ patients. Only 1 patient with VUR grade V had spontaneous resolution during follow-up.

There is no significant difference of spontaneous resolution with clinical treatment when boys and girls are compared. The resolution of VUR was not affected by age at entry. As to the laterality of VUR, there was no significant difference of cure for unilateral or bilateral VUR for grades I, II and III ( $\mathrm{p}=$ $0.731 ; p=0.344 ; p=0.204$, respectively). However, for patients with VUR grade IV, there was spontaneous resolution in 8 patients with unilateral $(19 \%)$ disease and in only 1 case of bilateral VUR $(3.1 \%)(\mathrm{p}=$ $0.068)$.

Table 4 - Characteristics of patients studied $(n=511)$.

\begin{tabular}{lccccc}
\hline & Grade I & Grade II & Grade III & Grade IV & Grade V \\
\hline $\mathrm{N}$ & 48 & 192 & 174 & 74 & 23 \\
Mean age & 2.3 years & 1.7 years & 1.5 years & 2.7 years & 1.3 years \\
& $(30 \mathrm{~d}-10 \mathrm{a})$ & $(44 \mathrm{~d}-9.3 \mathrm{a})$ & $(27 \mathrm{~d}-8,5 \mathrm{a})$ & $(0 \mathrm{~d}-10 \mathrm{a})$ & $(0 \mathrm{~d}-8 \mathrm{a})$ \\
Girl : Boy & $42: 6$ & $163: 29$ & $138: 36$ & $58: 16$ & $12: 11$ \\
Renal scars* & $3(6.2 \%)$ & $17(8.8 \%)$ & $22(12.6 \%)$ & $36(48.6 \%)$ & $20(87 \%)$ \\
UTI & $18(37.5 \%)$ & $44(23 \%)$ & $50(28.7 \%)$ & $24(32.4 \%)$ & $* *$ \\
UTI with fever & $3(6.2 \%)$ & $33(17.2 \%)$ & $37(21.2 \%)$ & $20(27 \%)$ & $* *$ \\
Surgery & $3(6.2 \%)$ & $20(10.4 \%)$ & $35(20.1 \%)$ & $45(60.8 \%)$ & $22(95.6 \%)$ \\
\hline
\end{tabular}

* Renal scars detected through DMSA or intravenous urography at the moment of the diagnosis; ** Anti-reflux surgery was performed in almost all patients with grade $V$.

Table 5 - The probability of reflux resolution with continuous antibiotics prophylaxis has been documented at 2 and 5 years after diagnosis.

\begin{tabular}{lccccc}
\hline Time of Follow-up & Grade I & Grade II & Grade III & Grade IV & Grade V \\
\hline 2 years & $40 \%$ & $24.3 \%$ & $16.2 \%$ & $7.3 \%$ & $*$ \\
& $(24.9-53.4 \%)$ & $(18-30.7 \%)$ & $(10.5-22 \%)$ & $(0.4-14.2 \%)$ & \\
5 years & $83 \%$ & $60.1 \%$ & $40.5 \%$ & $12.7 \%$ & $*$ \\
& $(71.6-94.4 \%)$ & $(52.6-67.7 \%)$ & $(33.2-48.8 \%)$ & $(2.9-22.6 \%)$ & \\
\hline
\end{tabular}

*VUR did resolve in just one of the children with grade $V$, and therefore the probability of reflux resolution was not produced. 


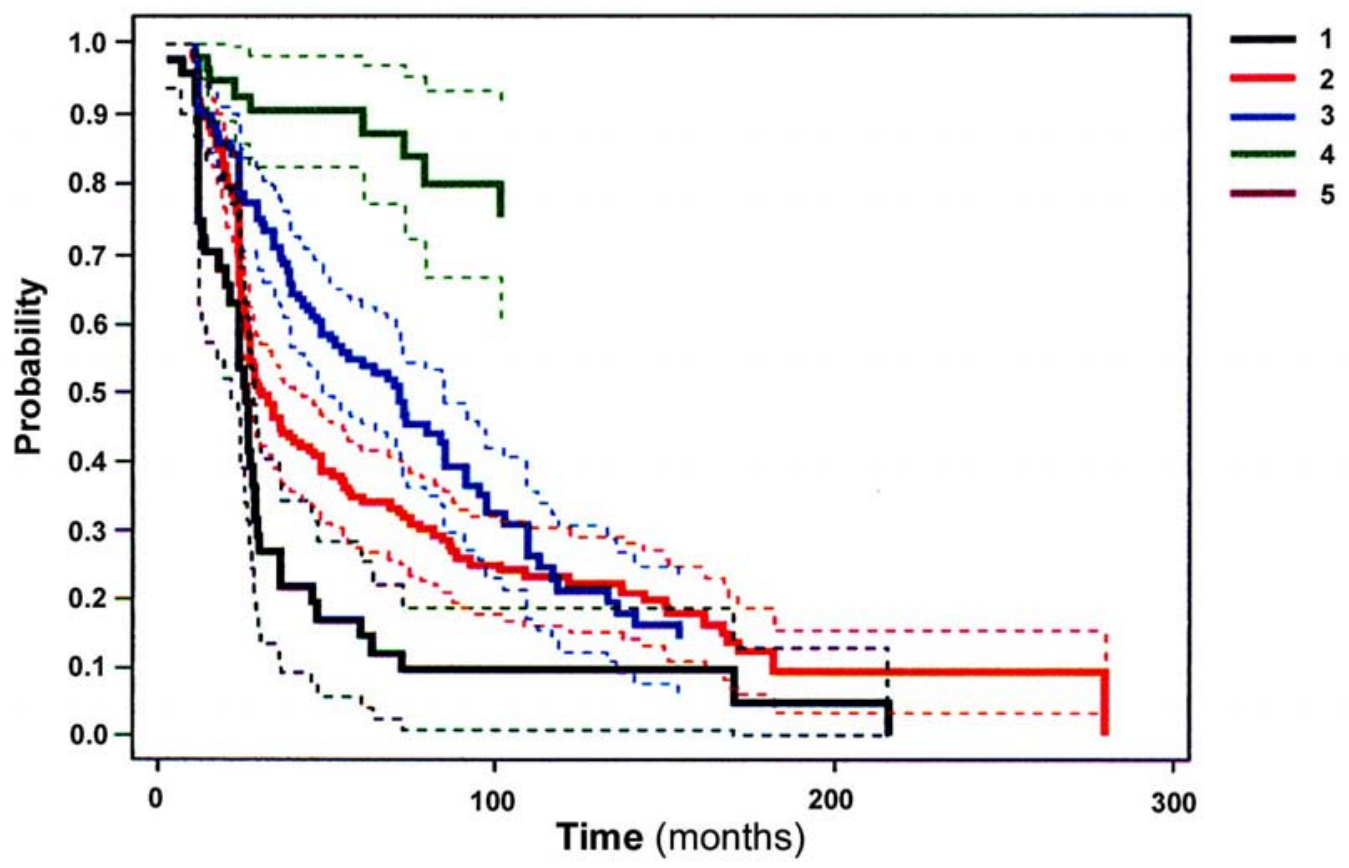

Figure 3 - Kaplan-Meier survival curves with 95\% of confidence interval showing the probability of vesicoureteral reflux resolution, in months, according to grade.

The analysis of Kaplan-Meier curves (Figure-3) showed a significant difference $(p<0.0001)$. Table-5 shows the probability of spontaneous cure of VUR at 2 and 5 years of follow-up based on a transversal section of the Kaplan-Meier curves.

\section{COMMENTS}

Despite the large number of children with reflux, management among urologists is still controversial. One of the most debated aspects is the choice between observation or surgical treatment. Although there is no consensus for the treatment of VUR in childhood, several principles based on literature data and corroborated by this study may be used as parameters when choosing optimal therapy for each case.

Chronic reflux nephropathy is a well known and feared disease and is the cause of chronic renal failure in up to $25 \%$ of children undergoing dialysis and in 10 to $15 \%$ of adults waiting for renal transplantation (7).

Several factors are taken into consideration when choosing therapy for VUR, such as: age, VUR grade, presence of renal injury, history of urinary infections and tolerance to antibiotics. The prevention of irreversible renal injury is the final goal of any of the therapeutic modalities, and so far there is no evidence of the superiority of clinical treatment over surgical therapy (8).

Wheeler et al. (8) recently perform a metaanalysis of seven trials with 833 evaluated patients comparing antibiotic prophylaxis with combined surgery and antibiotics to obtain summary measures of treatment effects. This systematic review of randomized controlled trials of interventions for children with vesicoureteral reflux has identified a number of important and unanswered questions. Most importantly, it is not clear whether any intervention for children 
with primary vesicoureteral reflux does more good than harm. Assuming intervention is beneficial, it is not clear whether antibiotics alone or reimplantation surgery alone are most effective in reducing the risk of urinary tract infection and renal parenchymal abnormality. Furthermore, the trials, which have been undertaken comparing surgery and antibiotics with antibiotics alone, have not shown any additional benefit of surgery except for a reduction in risk of febrile urinary tract infections.

Because of the good results obtained with clinical therapy using low dose antibiotics, in addition to the fact that there are few prospective, randomized, studies comparing clinical treatment to surgery (9-11), the large majority of children with VUR is clinically treated. Thus, high rates of spontaneous resolution are obtained, which depend especially on VUR grade and age at the time of diagnosis.

The most frequent clinical abnormality leading to the diagnosis of VUR is UTI. In our series, $85 \%$ of the children had UTI as an early manifestation. Recent studies have shown that other causes, such as antenatal hydronephrosis and voiding dysfunction have played a larger role in the diagnosis of VUR (12). In the evaluation of International Reflux Study in Children (IRSC) (10), UTI was observed in $89 \%$ to 92\% of children with VUR, and in approximately $30 \%$ of the cases there was some degree of renal injury at the time of diagnosis.

Of the 511 patients in this study, $98(19.2 \%)$ had renal scars at the time of diagnosis, and scarring was significantly more frequent in patients with VUR grades IV and V (48.6\% and $87 \%$ respectively). Greenfield et al. (12), in a study with 1040 children, diagnosed renal scarring in 13\% of the cases, of which $22 \%$ did not have a prior history of UTI. The stratification of patients in three different periods of time according to the time of diagnosis (Groups A, B and C) allowed us to carry out a critical analysis of the long-term outcome of VUR therapy. As occurs in IRSC (10), most children in the first period of our study (98.7\%) underwent intravenous urography for the assessment of the upper urinary tract, and this method was replaced by RUS and DMSA scan in the subsequent periods. There was a clear change in the renal assessment of patients with VUR.
The incidence of renal scarring at the time of VUR diagnosis was $31.2 \%$ in the first period (Group A) against $13.7 \%$ in the last group (Group C). A probable explanation for the high incidence of renal scars in the first period (group A) is a combination of many factors. First of all in the 1970s and early 1980s It was not a common practice for infants following their first diagnosed UTI to be referred to routine diagnostic imaging and we know that The likelihood of developing renal scars depends on factors such as the number of symptomatic UTI and the delay in their treatment. Actually the importance of prompt treatment of urinary infection or symptomatic recurrence of UTI was emphasized to local physicians. A second explanation is that patients admitted until the end of the 80's had a greater risk of UTI than children with a diagnosis of VUR after 1990. Possibly, this fact reflects an improvement in our understanding of the risk factors for UTI in this population, especially the recognition and treatment of voiding dysfunction and constipation.

In $24.5 \%$ (125/511) of the cases, surgical procedures were carried out to repair VUR. Skoog et al. (13) and Greenfield et al. (12), using similar indication criteria, reported $14 \%$ to $20 \%$ of surgical treatment. The surgical indications decreased from $30 \%$, in the first period, to $17.2 \%$ in the last, following the currently used criteria. This decrease is probably related to a better understanding of the disease and more adequate follow-up of these children. Despite the excellent success rates following antireflux surgery one has to bear in mind that surgery only corrects the anatomical abnormality. The long-term outcome with regard to renal function, urinary tract infections and arterial hypertension does not differ significantly from the medication group.

In our study, the Kaplan-Meier curves of VUR resolution show a clear relationship between the possibility of cure and the follow-up time, showing that VUR grades I and II were cured significantly faster than grades III and IV. Other authors $(8,14)$ have mentioned similar results. The information regarding the probability of resolution is essential when passing information onto the parents and choosing the best therapy to be adopted. Our spontaneous cure results are in agreement with those of other studies $(15,16)$. Schawab et al. (8) have reported $83 \%$ and 
$76 \%$ of spontaneous regression for grades I and II respectively. Tamminen-Mobius et al. (17) obtained resolution in $63 \%$ of VUR grade II and $50 \%$ in grade III. In our casuistic we obtained $87.5 \%$ of spontaneous cure for grade I, $77.6 \%$ for grade II and $52.8 \%$ for grade III, when the follow-up period is taken into consideration. The spontaneous resolution of VUR grade IV with clinical therapy is known to be low. In our study, the expected probability of cure at 5 years is only $12.2 \%$. Results have shown a spontaneous cure ranging from 9 to $16 \%$ in patients with VUR grade IV $(13,16)$.

The well-known association between vesicoureteral reflux and urinary tract infection is the basis for pathophysiological and therapeutic implications, which have dominated the literature on the subject for the last 3 decades. The pathogenesis of renal damage in children with VUR is controversial, as the exact role of UTI and pressure effects of sterile reflux on the developing kidneys is still unknown.

Primary VUR diagnosed after prenatal hydronephrosis is usually severe and is often associated to a congenital renal scars, which is primary and not the result of UTI. In our study diagnosis of VUR resulting from antenatal hydronephrosis were observed only in $15(3 \%)$ children. This type of VUR affects male more than female infants and the male predominance is thought to be secondary to a transient infravesical obstruction during pregnancy. This specific group of children achieves up to $43 \%$ of spontaneous cure for grades IV and V (18-20). Although in the first type of reflux renal scarring is often present at diagnosis, then probably congenital, it may always progress after UTI; hence the importance of early diagnosis and careful follow-up in each infant with primary VUR.

Our results showed that the incidence of reflux-related morbidity in children has significantly diminished over the last three decades. In our country, the rates of reflux-related nephropathy are much less than reported historically and are consistent with the most recently reported international data.

In our experience, and based on current knowledge and guidelines, which derive from a thorough review of the literature the recommendation of a treatment strategy for VUR is not, however, straightforward. In deciding whether to recommend surgical correction of VUR, factors that should be considered to include the previous and potential future morbidity of VUR in that individual, the risk of uncorrected VUR, the likelihood of spontaneous resolution or significant reduction in VUR, the efficacy and complications of medical therapy, the morbidity and discomfort associated to serial screening for VUR, the benefits and risks of surgical therapy, and economic factors.

The probability of spontaneous resolution of VUR forms the basis of the decision to treat using antibiotic prophylaxis. Undoubtedly, the most relevant finding in our clinical study is the rates of spontaneous resolution in a large Brazilian cohort.

Because the chance of spontaneous resolution is as high as $87.5 \%, 77.6 \%$ and $52.8 \%$ in VUR grades I, II and III, respectively, only exceptional cases should undergo primary surgical correction.

The different procedures should be analyzed for their costs in order to optimize the therapeutic strategy in different health systems. An individualized strategy seems to be the ultimate goal and should take into consideration the large number of issues.

\section{CONCLUSION}

In conclusion, urinary tract infection is still the major cause of VUR diagnosis. However, early diagnosis and adequate treatment allowed a significantly decrease of morbidity caused by renal injury. The currently employed clinical treatment might be safely used in most of the cases. Spontaneous resolution is directly related to VUR severity and is less likely to occur in grades IV and $\mathrm{V}$ for which surgery is a more adequate alternative.

\section{CONFLICT OF INTEREST}

None declared.

\section{REFERENCES}

1. Jodal U, Koskimies O, Hanson E, Lohr G, Olbing H, Smellie J, et al.: Infection pattern in children with 
vesicoureteral reflux randomly allocated to operation or long-term antibacterial prophylaxis. The International Reflux Study in Children. J Urol. 1992; 148: 1650-2.

2. Wingen AM, Koskimies O, Olbing H, Seppanen J, Tamminen-Mobius T: Growth and weight gain in children with vesicoureteral reflux receiving medical versus surgical treatment: 10-year results of a prospective, randomized study. International Reflux Study in Children (European Branch). Acta Paediatr. 1999; 88: 56-61.

3. [No authors listed]: Medical versus surgical treatment of primary vesicoureteral reflux: report of the International Reflux Study Committee. Pediatrics. 1981; 67: 392400.

4. Smellie JM: The intravenous urogram in the detection and evaluation of renal damage following urinary tract infection. Pediatr Nephrol. 1995; 9: 213-9; discussion 219-20.

5. Goldraich NP, Ramos OL, Goldraich IH: Urography versus DMSA scan in children with vesicoureteric reflux. Pediatr Nephrol. 1989; 3: 1-5.

6. Merguerian PA, Jamal MA, Agarwal SK, McLorie GA, Bagli DJ, Shuckett B, et al.: Utility of SPECT DMSA renal scanning in the evaluation of children with primary vesicoureteral reflux. Urology. 1999; 53: 1024-8.

7. Bailey RR, Mailing TMJ, Swainson CP: Vesicoureteric reflux and reflux nephropathy. In: Scherier RW, Gottschalk CW (eds.), Disease of the Kidney, Fifth edition. Boston, Litthe, Brown \& Co. 1993; pp. 689727.

8. Wheeler D, Vimalachandra D, Hodson EM, Roy LP, Smith G, Craig JC: Antibiotics and surgery for vesicoureteric reflux: a meta-analysis of randomised controlled trials. Arch Dis Child. 2003; 88: 688-94.

9. Birminghan Reflux Study Group: Prospective trial of operative versus non operative traitement of severe vesico-ureteric reflux in children: five years observation. Brit Med J. 1987; 295: 237-41.

10. Weiss R, Tamminen-Mobius T, Koskimies O, Olbing H, Smellie JM, Hirche H, et al.: Characteristics at entry of children with severe primary vesicoureteral reflux recruited for a multicenter, international therapeutic trial comparing medical and surgical management. The International Reflux Study in Children. J Urol. 1992; 148: 1644-9.

11. Scholtmeijer RJ: Treatment of vesicoureteric reflux: results after 3 years in a prospective study. Child Nephrol Urol. 1991; 11:29-32.

12. Greenfield SP, Ng M, Wan J: Experience with vesicoureteral reflux in children: clinical characteristics. J Urol. 1997; 158: 574-7.

13. Chand DH, Rhoades T, Poe SA, Kraus S, Strife CF: Incidence and severity of vesicoureteral reflux in children related to age, gender, race and diagnosis. J Urol. 2003; 170: 1548-50.

14. Skoog SJ, Belman AB, Majd M: A nonsurgical approach to the management of primary vesicoureteral reflux. J Urol. 1987; 138: 941-6.

15. Elder JS, Peters CA, Arant BS Jr, Ewalt DH, Hawtrey CE, Hurwitz RS, et al.: Pediatric Vesicoureteral Reflux Guidelines Panel summary report on the management of primary vesicoureteral reflux in children. J Urol. 1997; 157: 1846-51.

16. Arant BS Jr: Medical management of mild and moderate vesicoureteral reflux: followup studies of infants and young children. A preliminary report of the Southwest Pediatric Nephrology Study Group. J Urol. 1992; 148: 1683-7.

17. Tamminen-Mobius T, Brunier E, Ebel KD, Lebowitz R, Olbing H, Seppanen U, et al.: Cessation of vesicoureteral reflux for 5 years in infants and children allocated to medical treatment. The International Reflux Study in Children. J Urol. 1992; 148: 1662-6.

18. Duckett JW: Vesicoureteral reflux: a 'conservative' analysis. Am J Kidney Dis. 1983; 3: 139-44.

19. Yeung CK, Godley ML, Dhillon HK, Gordon I, Duffy PG, Ransley PG: The characteristics of primary vesicoureteric reflux in male and female infants with pre-natal hydronephrosis. Br J Urol. 1997; 80: 319-27.

20. Sillen U, Hjalmas K, Aili M, Bjure J, Hanson E, Hansson S: Pronounced detrusor hypercontractility in infants with gross bilateral reflux. J Urol. 1992; 148: 598-9.

Correspondence address: 


\section{EDITORIAL COMMENT}

Vesicoureteral reflux (VUR) was originally described in medieval times; the first ureteral reimplantation to correct VUR was performed in the late 19th century. Despite the intervening centuries and their numerous accompanying medical advances, reflux remains in the 21 st century a vexing management problem for the urologist. The traditional therapeutic options of antibiotic chemoprophylaxis and open ureteroneocystostomy are increasingly being challenged in the United States and Europe by newer technologies such as endoscopic injection of bulking agents and laparoscopic or robotic ureteroneocystostomy. It remains unclear which of these techniques, if any, will ultimately become the worldwide standard of care. Diverse issues such as cost, cosmesis, and efficacy have yet to be fully determined on all of these treatment modalities, and will ultimately need to be balanced against one another. Against this backdrop of uncertainty, it is critical that the urologist treating VUR

\section{EDITORIAL COMMENT}

I congratulate the authors on a detailed study of children born with vesicoureteral reflux (VUR). Despite the retrospective nature, the thorough review of data produced useful information that is extremely relevant today when endoscopic therapy is being popularized. The authors point out that the goal of treating this disorder is prevention of infections and scarring. As I teach our residents, there is a difference in treating "children with reflux" and treating "reflux."

This manuscript reiterates known rates of spontaneous resolution. These high rates of resolution understand the natural history of the disease. The authors are to be credited for their efforts with this study, a large, retrospective, population-based cohort of over 500 Brazilian children. As the study spans a 30 -year period, the authors are in a unique position to comment on the evolution of VUR evaluation and management. It is noteworthy that both surgical intervention and renal scarring were significantly reduced in the most recent cohort, particularly in light of the fact that the proportion of high-grade VUR remained relatively constant. I agree with the authors that this is likely due to earlier diagnosis. Although the urologic community may argue about what exactly the optimal treatment modality for VUR is in the 21st century, these data would seem to imply that we are nonetheless able to agree that some treatment is required to prevent long-term renal dysfunction. This study would appear to support the notion that we are succeeding in that regard.

\author{
Dr. Jonathan C. Routh \\ Department of Urology \\ Mayo Clinic \\ Rochester, Minnesota, USA \\ E-mail: routh.jonathan@mayo.edu
}

need to be considered in light of presentation in this series, only $3 \%$ were found on workup for antenatal hydronephrosis. In the United States, many more patients are diagnosed with VUR following fetal sonography. As pointed out in the discussion, children diagnosed early by fetal sonography have an even higher rate of spontaneous resolution, including highgrade VUR. Given ample opportunity, most children with low-grade reflux will resolve the problem without surgical therapy, and children diagnosed by fetal sonography have an excellent chance for resolution of all grades. 
As exemplified in this article and others, most scarring is congenital and few children develop cortical loss while under medical therapy. Knowing this, any surgical therapy will likely only achieve a lower incidence of infection and add little benefit over antibiotics to prevention of scarring. This has been demonstrated in several studies (1). Since long-term, low dose antibiotics are known to be safe (2), one has to question the determination to treat younger and younger patients surgically (3), removing any hope of a natural cure. The advent of endoscopic treatment appears to have clouded our goals in treating this disorder. There is no better repair than spontaneous resolution. In the 1990's we were discussing observation off antibiotics. Somehow, in the $21 \mathrm{st}$ century we have regressed to discussing surgical treatment of non-refluxing ureters and orifices that dilate during cystoscopy. Dr. Filho's manuscript reminds us that spontaneous resolution is likely with patience.

\section{REFERENCES}

1. Wheeler D, Vimalachandra D, Hodson EM, Roy LP, Smith G, Craig JC: Antibiotics and surgery for vesicoureteric reflux: a meta-analysis of randomised controlled trials. Arch Dis Child. 2003; 88: 688-94.

2. Karpman E, Kurzrock EA: Adverse reactions of nitrofurantoin, trimethoprim and sulfamethoxazole in children. J Urol. 2004; 172: 448-53.

3. Puri P, Pirker M, Mohanan N, Dawrant M, Dass L, Colhoun E: Subureteral dextranomer/hyaluronic acid injection as first line treatment in the management of high grade vesicoureteral reflux. J Urol. 2006; 176: 18569; discussion 1859-60.

Dr. Eric A. Kurzrock Chief, Pediatric Urology University of California, Davis Children's Hospital Sacramento, California, USA E-mail: eric.kurzrock@ucdmc.ucdavis.edu

\section{EDITORIAL COMMENT}

The authors detail their 30 year experience in 511 children with reflux; the majority of patients presenting with urinary infection. These children, with no confounding anatomic or neurological abnormalities presented at a mean age of 3.1 years and were followed for a median of 2.7 years. The distribution of grades and spontaneous resolution rates were congruent with those reported in previous studies. Surgical correction was reserved for approximately $25 \%$ of the original cohort.

This study reminds us that the majority of cases of mild to moderate reflux will resolve with time. It also underscores the evolution in our management paradigms for this condition (1). In the early decade of this study, reflux was widely considered by urologists as an anatomic abnormality requiring surgical correction in all patients. Later, owing in large part to the seminal work of Smellie et al. we learned that the majority of children did well on prophylactic antibiotics until reflux resolved. Surgery was reserved for the few failing this approach (2). More recently, urologists have come to realize that at some point in a child's development, reflux, even if persistent, becomes a radiographic finding only and is no longer a threat to health. At that juncture, antibiotics can be safely withdrawn regardless of the status of the reflux (3- 
6). Surgery is then reserved for those who experience pyelonephritis off of medical treatment. Concomitant with this approach, a competing philosophy has arisen: immediate injection therapy shortly after initial diagnosis of reflux (7). This latter approach has been gaining popularity owing in no small way to the development of the first FDA approved injectable agent in 2001. Preliminary data suggest that injection rates for vesicoureteral reflux have risen sharply in the United States in the last few years (8). In addition, there are increasing concerns over the safety and lack of evidence regarding the efficacy of long-term low dose antibiotic use in children (9-11). Despite 55 years since Hutch first described the relationship between pyelonephritis and reflux in paraplegics (12) we still require well designed prospective randomized controlled trials comparing long-term renal outcomes in patients undergoing conventional medical and surgical management versus observation without antibiotic suppression. Until such time that this information is available, we need to be cautious regarding the enthusiastic adoption of new surgical interventions just because they offer relatively simple and quick closure.

\section{REFERENCES}

1. Wan J: Editorial comment. J Urol. 2002; 168: 707.

2. Edwards D, Normand IC, Prescod N, Smellie JM: Disappearance of vesicoureteric reflux during long term prophylaxis of urinary tract infection in children. $\mathrm{Br}$ Med J. 1977; 2 (6082): 285-8.

3. Cooper CS, Chung BI, Kirsch AJ, Canning DA, Snyder HM: The outcome of stopping antibiotics in older children with vesicoureteral reflux. J Urol. 2000; 163: 269-72, discussion 272-3.

4. Thompson RH, Chen JJ, Pugach J, Naseer S, Steinhardt GF: Cessation of prophylactic antibiotics for management of persistent vesicoureteral reflux. J Urol. 2001; 166: 1465-9.

5. Al- Sayyad AJ, Pike JG, Leonard MP: Can prophylactic antibiotics safely be discontinued in children with vesicoureteral reflux? J Urol. 2005; 174 (4 pt 2): 1587-9.

6. Georgaki-Angelaki H, Kostaridou S, Daikos GL, Kapoyiannis A, Veletzas Z, Michos AG, et al.: Longterm follow-up of children with vesicoureteral reflux with and without antibiotic prophylaxis. Scan J Infect Dis. 2005; 37: 842-5.

7. Puri P, Priker M, Mohanan N, Dawrant M, Dass L, Colhoun E: Subureteral Dextranomer / Hyaluronic acid injection as first line treatment in the management of high grade vesicoureteral reflux. J Urol. 2006; 176: 185660.

8. Lendvay TS, Sorensen M, Cowan CA, Joyner BD, Mitchell MM, Grady RW: The evolution of vesicoureteral reflux management in the era of Dextranomer / Hyaluronic acid copolymer: A pediatric health information system database study. J Urol. 2006; 176: 1864-7.

9. Le Saux N, Pham B, Moher D: Evaluating the benefits of antimicrobial prophylaxis to prevent urinary tract infections in children. A systematic review. CMAJ 2000; 163: 523-9.

10. Velicer CM, Heckbert SR, Lampe JW, Potter JD, Robertson CA, Taplin SH: Antibiotic use in relation to the risk of breast cancer. JAMA. 2004; 291: 827-35.

11. Allen UD, MacDonald N, Fuite L, Chan F, Stephens D: Risk factors for resistance to "first-line" antimicrobials among urinary tract isolates of Escherichia coli in children. CMAJ. 1999; 160: 1436-40.

12. Hutch JA: Vesicoureteral reflux in the paraplegic: cause and correction. J Urol. 1952; 68: 457-69.

Dr. Andrew E. MacNeily Head, Division of Pediatric Urology University of British Columbia Children's Hospital Vancouver, British Columbia, Canada E-mail: amacneily@cw.bc.ca 